Illustro, ISSN 2311-4126, 2014, vol.5, 35-49

\title{
EFECTIVIDAD DE LA CAMPAÑA "HABLEMOS MÁS SIMPLE": EL ANTES Y DESPUÉS DE LA BANCARIZACIÓN EN LA CIUDAD DE AREQUIPA
}

\author{
EFFECTIVENESS OF THE CAMPAIGN "LET'S TALK MORE SIMPLE”: \\ BEFORE AND AFTER THE BANKING \\ IN THE CITY OF AREQUIPA
}

Andrea L. Pajtak Chambi y Bruno F. Rodríguez Núñez Universidad Católica San Pablo, Arequipa, Perú

\section{Resumen:}

En el presente artículo se exponen los resultados de un estudio causal-comparativo que pretende determinar la efectividad de la Campaña "Hablemos más Simple" en el nivel de bancarización de Arequipa. Se obtuvo información de tres fuentes oficiales: Asociación de Bancos del Perú (ASBANC), Instituto Nacional de Estadística e Informática (INEI) y Banco Central de Reserva del Perú (BCRP), con la cual se elaboraron los ratios para determinar el nivel de bancarización en la ciudad. Se trabajó con una ficha de registro donde se anotaron todos los datos recolectados de las fuentes antes mencionadas. Trabajando con un nivel de significancia de 99\% (p< o.o1), se encontraron diferencias significativas en las variaciones experimentadas por todos los indicadores hallados, excepto el de tarjetas de crédito sobre PEA. Todo ello da cuenta del cambio en el nivel de bancarización en la ciudad y el efecto provocado por de la Campaña "Hablemos más Simple".

Palabras clave: Bancarización, efectividad, servicios financieros.

\section{Summary:}

The present article presents the results of a causal-comparative study, so we can determine the effectiveness of the campaign "Let's Talk More Simple" in the level of banking 
of Arequipa. Information was obtained from three official sources: Association of Banks of Peru (ASBANC), National Institute of Statistics and Informatics (INEI) and Central Reserve Bank of Peru (BCRP), with which the ratios were developed to determine the level of banking in the city. We worked with a tab where we wrote down all the data collected from the sources mentioned above. Working with a significance level of $99 \%$ $(\mathrm{p}<\mathrm{o.01})$, significant differences were found in the variations experienced by all the indicators found, except the credit cards of the PEA. All of that gives an account of the change in the level of banking in the city and the effect caused by the campaign "Let's Talk More Simple".

Key words: Banked, effectiveness, financial services.

\section{Introducción}

Toda persona, familia o empresa al momento de recibir un ingreso se enfrenta a dos decisiones, resolver qué porcentaje de ese ingreso se gasta y qué porcentaje se destina al ahorro. Con el objeto de llevar todo movimiento económico a la formalidad, nace la bancarización. Consiste entonces en hacer usos de las instituciones financieras para todo movimiento de capitales (Burneo, 2009).

En un concepto amplio, la bancarización podría definirse como "el acceso a los servicios financieros por parte de la población" (IPSCuba, 2010, Párr. 2). De manera más detallada se refiere a la utilización masiva del sistema financiero por parte de las personas para la realización de transacciones financieras o económicas, incluyendo no solo los tradicionales servicios de crédito y ahorro, sino también la transferencia de recursos y la ejecución de pagos a través de medios electrónicos, cajeros, productos bancarios, agencias bancarias y dispositivos electrónicos disponibles en la red bancaria.

Aunque los métodos para la determinación del nivel de bancarización de una nación no son estandarizados y cada territorio se vale de diversas metodologías, la mayoría de los especialistas concuerdan que un alto nivel de bancarización en un determinado territorio es signo de crecimiento y posterior desarrollo económico (Conde, 2007). Por esto, aunque la bancarización siempre ha estado presente, ha cobrado más relevancia en los últimos años, al identificarse la importancia del sistema financiero en el desarrollo de las sociedades, pues es mediante el uso de los servicios prestados por éste que las empresas y las personas en general pueden gozar de mayor liquidez, aumentando su poder de gasto, por tanto el consumo e inversión, siendo este último el principal factor desencadenante del crecimiento económico (Furtado, 1974).

Tradicionalmente este concepto ha sido medido como el ratio de depósitos totales del sistema en relación al PBI, hoy se suman a su análisis ratios varios que responden a la amplitud de su definición, como el porcentaje de créditos en relación al PBI, número de tarjetas de débito y crédito por cada 10o,ooo habitantes, número de cajeros/ATM y sucursales de entidades financieras para igual número de habitantes, etc. (Inga, 2010). Además pueden 
considerarse indicadores que señalen el porcentaje de la población que usa diversos servicios financieros, como cuentas de ahorro, cuentas corrientes u otros servicios y sus distintas modalidades.

En un trabajo de Loayza, Fajnzylber y Calderón (2005), se describen las características básicas del crecimiento para un grupo representativo de países de América Latina y el Caribe y se explica las diferencias en el crecimiento económico entre ellos, además de identificar determinantes básicos del crecimiento sobre los cuales se hacen proyecciones. Estos determinantes se sistematizan en 5 grupos: a) Convergencia Transicional, donde la tasa de crecimiento depende de la posición inicial de la economía y por la existencia de rendimientos decrecientes, la tasa de crecimiento es mayor en los países pobres que en los ricos. b) Reversión Cíclica, factor que permitiría capturar el efecto del ciclo económico por lo que se incluye la brecha del producto como determinante del crecimiento permitiendo evitar a la vez sobrestimar la velocidad de la convergencia transicional. c) Políticas Estructurales e Instituciones, dentro de las políticas estructurales incluye a la educación, la participación del gasto público en el PBI, la apertura al comercio internacional, la gobernabilidad y al desarrollo financiero.

Sobre este último aspecto, se ha encontrado una asociación directa y estadísticamente significativa con el crecimiento económico, ello lo explican en tanto consideran que un sistema financiero funcionando adecuadamente incide en la eficiencia económica y en el crecimiento a través de varios canales: los mercados financieros facilitan la diversificación del riesgo a través de la comercialización, profundización y cobertura de instrumentos financieros. Pueden ayudar además a identificar proyectos de inversiones rentables y movilizar ahorros hacia ellos. Incluso los sistemas financieros pueden también ayudar a monitorear a gerentes de firmas y ejercer control corporativo, reduciendo así el problema agente/principal que conduce a inversión ineficiente.

Finalmente en este trabajo, las otras dos determinantes de las variables explicativas del crecimiento son d) las políticas de estabilización y e) las condiciones externas.

Por tanto, un alto nivel de bancarización representa beneficios desde tres aristas distintas: para el Banco entendido como corporación, para sus distintas sucursales o puntos de venta y para los clientes (Araya y cols., 2012). En el caso del Banco o institución financiera, los beneficios contemplados serían: aumenta su cobertura geográfica, da nuevas oportunidades de negocio, traslada flujos de personas de las oficinas tradicionales a otros sitios (descongestión), reduce costos operacionales, aumenta el número de clientes y se convierte en un nuevo canal de alta rentabilidad. Para los distintos puntos de venta o agentes bancarios, los beneficios incluyen: aumento de flujo de personas en el establecimiento, valoriza el punto de venta, incrementa las ventas, fideliza los clientes, incrementa sus ingresos al recibir comisiones del banco y reducción del riesgo operativo con el efectivo. La tercera arista constituida por los clientes, reporta los siguientes beneficios: comodidad y conveniencia al momento de llevar a cabo transacciones, mayor seguridad al no cargar efectivo, mayores posibilidades 
de acceso al crédito, ya sea de consumo o para inversión, beneficio por tasas pasivas y elección entre una gama de servicios financieros (Almendárez, 2008).

A nivel mundial, los índices más altos de bancarización se relacionan con los países más desarrollados, destacando Alemania con 85\% y Estados Unidos con 82\% (Luzón, 2002). En Latinoamérica, según la Superintendencia de Banca y Seguros (2012), los niveles de bancarización a junio del 2011 no superaban el 50\%, con excepción de Chile y Panamá, con niveles de $63.54 \%$ y $54.42 \%$, respectivamente.

Según Almendárez (2008), para un informe del GBM Journal, las causas principales del bajo nivel de bancarización en Latinoamérica serían los elevados niveles de pobreza e informalidad, ausencia o incapacidad para demostrar existencia de garantías, altos costos en la transacción, dispersión geográfica de la población, limitada información sobre productos financieros disponibles y bajo nivel educativo y de cultura financiera.

Dichos factores coinciden con algunos de los planteados por la ONU en el libro "Bancarización Privada en Chile" (Zahler, 2010), donde el autor Roberto Zahler, Consultor de la Unidad de Estudios de Desarrollo en la mencionada institución, comenta que los principales factores por los cuales la bancarización es baja en América Latina se dan en dos grandes ámbitos: el primero lo constituye el desarrollo económico y social, donde se encuentran factores como la credibilidad en las instituciones, cumplimiento de contratos, equilibrios macro-económicos, niveles de ingresos económicos de la población, educación e informalidad de las empresas.

El segundo ámbito lo conforma la organización industrial, donde figuran la concentración bancaria y los costos fijos en la captación de un cliente, la evaluación de un crédito, su desembolso, seguimiento y recaudación.

En el caso de nuestro país, la evolución de la bancarización ha sido cuando menos prodigiosa aunque aún no sea suficiente; mientras en la investigación realizada por la CEPAL en el 2005, nuestro país se encontraba debajo del nivel de bancarización de Venezuela ( $11 \%$ en aquel entonces), al día de hoy la cifra bordea el 30\% (Superintendencia de Banca y Seguros, 2010).

Según el diario Gestión, para el 2008, la bancarización en el Perú se había elevado ocho puntos porcentuales con respecto al 2002, alcanzando el $28 \%$ aproximadamente para ese año. Para los años siguientes, a raíz de la crisis financiera internacional, el crecimiento de la bancarización peruana se estancó levemente. Acorde a lo dicho por el Gerente General de la Asociación de Bancos (ASBANC), Enrique Arroyo, el incremento del nivel de bancarización se explica por el incremento en la confianza de los ciudadanos en las instituciones financieras, además del dinamismo de la actividad económica experimentada en ese periodo (Arroyo, 2008).

Para el año 2010, según la Superintendencia de Banca y Seguros (SBS), la bancarización llegó al 30.2\% considerando el indicador de intermediación financiero que compara 
los depósitos totales del sistema financiero con el Producto Bruto Interno (PBI).

Al respecto la SBS explica que: "entre las razones que explican el continuo avance del proceso de bancarización en el país, está la descentralización económica observada en los últimos años y que ha mejorado el bienestar en la población de provincias" (SBS, 2010, párr. 9).

Además comenta que la mayor competencia en las microfinanzas, el fortalecimiento de entidades especializadas y el ingreso de bancos a este sector en específico, aunado al aumento de los canales de atención al público son factores favorables para el aumento de la bancarización. Contrario a lo que podría creerse, la SBS ha declarado que:

El avance en el proceso de bancarización en el país se registró principalmente en las provincias, donde se apreció un mayor dinamismo en el crecimiento de los depósitos y de los créditos, impulsados principalmente por las entidades que componen el sistema microfinanciero, como las cajas municipales, las cajas de ahorro y las edpymes, que son los que realizan el mayor esfuerzo por incorporar a más personas al sistema financiero. (SBS, 2010, párr.4)

De modo que el principal motor para el crecimiento de la bancarización en el país lo componen las medianas, pequeñas y micro empresas; que por sus grandes necesidades de crédito para el desarrollo empresarial, recurren a entidades microfinancieras.
Para diciembre del 2001, la Superintendencia de Banca y Seguros (SBS) emitió un informe señalando que el nivel de bancarización alcanzado por el Perú para esa fecha era de $30.84 \%$, tomando como referencia el ratio de depósitos sobre Producto Bruto Interno (SBS, 2011).

$\mathrm{Al}$ 2012, el Perú en niveles de bancarización aún se encuentra por debajo del promedio de países latinoamericanos, ocupando el puesto 15, Panamá y Chile encabezan la lista de países más bancarizados y es que cuentan con un sistema financiero sólido desde ya hace varios años (Jiménez \& Manuelito, 2012). Debido a factores político-legales el Perú recién se está encaminando en el recto sendero de la bancarización, se espera que para el año 2014, el país esté bancarizado en un 35\% planea la SBS (2012).

En el caso de Arequipa, la situación se presenta aún más favorable, pues según José Gómez de La Torre (2011), jefe de la Oficina Descentralizada de la Superintendencia de Banca y Seguros de Arequipa (SBS), explicó que el promedio de bancarización de nuestra ciudad superó el nivel de bancarización nacional, situándose en $34.08 \%$ frente al 30\% del país. Según de La Torre, el incremento en la bancarización arequipeña se debería a la reciente apertura de los megacentros comerciales, que privilegian el uso de créditos y tarjetas para la realización de las compras. Otro factor, indica, es la mayor cantidad de oficinas bancarias en la ciudad, pues mientras en el Perú por cada 100 mil habitantes existen 18 oficinas, en Arequipa el promedio es de 24 . 
Tabla 1.

Tasa de bancarización en países de América Latina

\begin{tabular}{|c|c|c|c|c|}
\hline \multicolumn{5}{|c|}{ Tasa de Bancarización 2012 América Latina } \\
\hline & País & $\begin{array}{c}\text { Depósitos Totales } \\
\text { (Mills US\$) }\end{array}$ & PBI (Mills US\$) & $\begin{array}{c}\text { Bancarización } \\
\text { (Dep. Tot/PBI) * }\end{array}$ \\
\hline 1 & Panamá & 49,616 & 30,569 & 1.62 \\
\hline 2 & Chile & 148,006 & 248,411 & 0.60 \\
\hline 3 & Nicaragua & 3,640 & 7,297 & $0.5^{2}$ \\
\hline 4 & Uruguay & 22,694 & 46,872 & 0.50 \\
\hline 5 & Honduras & 8,157 & 17,381 & 0.48 \\
\hline 6 & Costa Rica & 18,203 & 40,947 & 0.47 \\
\hline 7 & Paraguay & 8,912 & 21,236 & 0.45 \\
\hline 8 & El Salvador & 9,421 & 22,761 & 0.44 \\
\hline 9 & Bolivia & 9,116 & 24,604 & 0.42 \\
\hline 10 & Guatemala & 17,007 & 46,897 & 0.41 \\
\hline 11 & Venezuela & 112,016 & 315,841 & 0.38 \\
\hline 12 & Colombia & 98,602 & 328,422 & 0.36 \\
\hline 13 & Brasil & 701,689 & $2,492,908$ & 0.35 \\
\hline 14 & Ecuador & 18,070 & 66,381 & 0.32 \\
\hline 15 & Perú & 46,762 & 173,502 & 0.31 \\
\hline 16 & Rep. Dom. & 15,248 & 56,700 & 0.27 \\
\hline 17 & Argentina & 107,848 & 447,644 & 0.24 \\
\hline 18 & México & 212,559 & $1,154,784$ & 0.18 \\
\hline
\end{tabular}

*A Junio del 2012.

Fuente: FELABAN y FMI

Como se ha visto, el nivel de bancarización de un territorio determinado viene influenciado por factores como la cantidad de instituciones existentes, el acceso de la población a éstas, la información con la que cuenten los usuarios y la confianza en el sistema financiero. Con respecto a esto, la Asociación de Bancos del Perú (ASBANC), lanzó en junio del 2012 la Campaña "Hablemos más Simple", la cual constituye una iniciativa que tiene como objetivo "simplificar" el mensaje transmitido por las instituciones financieras participantes a sus prospectos y clientes en las estrategias de comunicación que estas brindan para informar a sus ahorristas sobre el rendimiento que tendrá su dinero depositado en el banco y/o el costo que deberán pagar los prestatarios por el dinero solicitado a la institución (Gestión, 2012). La finalidad de esta iniciativa es crear relaciones de entendimiento entre las personas y las empresas del sector financiero, buscando una comunicación efectiva, y además que se conciba que ambas partes tienen derechos y deberes que cumplir. "Los bancos del Perú estamos trabajando en 
una iniciativa para tener una comunicación más simple y fácil de entender, así nuestros clientes podrán tomar mejores decisiones" (ASBANC, 2012, párr. 2).

Bajo el uso de dos siglas propias del lenguaje Bancario: TREA y TCEA (Tasa de Rendimiento Efectivo Anual y Tasa de Costo Efectivo Anual), se crearon dos interpretaciones más sencillas que puedan ser entendidas por el público: Te Rinde y Te Cuesta, respectivamente (ASBANC, 2012). Estas siglas acompañadas de sus respectivos logos, constituyen la primera medida para informar a los usuarios acerca de los servicios del sistema financiero con respecto al funcionamiento de las tasas más comunes.

El propósito de informar a los usuarios acerca del sistema financiero con términos más comprensibles y "amigables" es el núcleo de esta campaña. De este modo, se pretende que la relación entre los bancos y la gente sea más confiable y fácil. Si este fuera el caso, el resultado de informar al público seria un aumento en el uso de los servicios del sector financiero y de la confianza de los usuarios, lo que se traduciría en un aumento de la bancarización. Por lo expuesto nos planteamos como problema de investigación, conocer si la Campaña "Hablemos más Simple” ¿habría sido efectiva en el aumento del nivel de bancarización de Arequipa?

\section{Método}

\section{Diseño de investigación}

Se trabajó con un diseño de investigación tipo causal comparativo a fin de establecer comparaciones entre los valores obtenidos en el nivel de bancarización de la ciudad de Arequipa antes y después de la aplicación de la campaña "Hablemos más Simple", y atribuir los cambios evidenciados a la implementación de la campaña en cuestión.

\section{Obtención de datos}

La obtención de datos se realizó por medio de tres fuentes oficiales, cuya información se utilizó para elaborar los ratios para determinar el nivel de bancarización:

- Asociación de Bancos del Perú (ASBANC) entidad que ideó e implementó la Campaña "Hablemos más Simple”.

- Instituto Nacional de Estadística e Informática (INEI): Entidad nacional recopiladora de datos de la población peruana en diversos sectores.

- Banco Central de Reserva del Perú (BCRP): Entidad autónoma que dictamina y norma a todas las instituciones financieras peruanas, además de determinar la política monetaria del país.

\section{Instrumentos}

Se trabajó con una ficha de registro que fue utilizada en el estudio de gabinete que realizaron los investigadores, recurriendo a la información brindada por los informes mensuales en las páginas web de las fuentes oficiales anteriormente mencionadas. A través de ésta se recogieron datos cuantitativos exactos de la situación de la bancarización en 
la ciudad de Arequipa, valiéndonos de indicadores y ratios como: Ratio Depósitos totales/PBI, Ratio Créditos totales/ PBI, Tarjetas de crédito/PEA, Tarjetas de crédito por cada 100,00o habitantes, Tarjetas de débito/PEA, Tarjetas de débito por cada 100,ooo habitantes, Número de cajeros (ATM) por cada 100,00o habitantes, Número de sucursales por cada 100,00o habitantes.

Además en el caso de los ratios de créditos y depósitos se desglosó cada uno por tipo de operación financiera, es decir, créditos para consumo y para negocios, y depósitos a la vista, de ahorro y a plazo.

Los datos e indicadores recogidos fueron registrados en los casilleros respectivos de la ficha, correspondientes a una evolución de seis meses: tres meses antes de la implementación de la Campaña "Hablemos, más Simple", y tres meses después de la aplicación de ésta (Periodo marzo-agosto del 2012).

\section{Procedimientos}

Los investigadores dedicaron un promedio de 12 horas semanales durante el mes de noviembre a la recolección de los datos necesarios para la obtención de ratios. Seguidamente, con la ayuda del Programa Microsoft Excel se procedió a obtener los ratios mensuales anteriormente indicados. Una vez calculados, se observó la evolución de los mismos a lo largo de los seis meses analizados. Para cada ratio se determinó si las diferencias mostradas antes y después de la Campaña "Hablemos más Simple” eran significativas, a través de la prueba $t$ student bilateral con un nivel de significancia equivalente a o.or. De este modo se pudo determinar qué aspectos habían variado comparativamente, antes y después en relación al nivel de bancarización.

\section{Resultados}

Se trabajó con los datos recolectados de las fuentes mencionadas, correspondientes a los meses marzo, abril, mayo, junio, julio y agosto. Los datos contemplaron información referida al PBI mensual de la ciudad, la PEA, número de cajeros automáticos, número de sucursales, los diferentes tipos de depósitos y créditos con sus respectivos montos y el número de tarjetas de crédito y débito en la ciudad.

Si analizamos al detalle, se puede apreciar que los depósitos que tienen una mayor proporción dentro de los totales, son los referidos a los depósitos de ahorros, que son el dinero que las personas depositan en alguna institución financiera, luego de haber cubierto sus gastos. Se ve también, que el ratio de Créditos totales sobre PBI, aumentó de manera constante desde el mes de marzo hasta julio, para luego presentar una ligera caída en el mes de agosto. Desglosando los datos al detalle, encontramos que los créditos de mayor proporción vienen representados por aquellos que están destinados a la labor productiva (créditos otorgados a las empresas), y dentro de éstos, las empresas que concentran la mayor cantidad de créditos en términos monetarios son las grandes corporaciones, frente a las microempresas, que representan el menor porcentaje en cuanto a créditos en términos monetarios (ver Tabla 3). 
Tabla 2.

Ratios con los distintos indicadores de medición

\begin{tabular}{|c|c|c|c|c|c|c|}
\hline \multirow{3}{*}{ RATIOS } & Marzo & Abril & Mayo & Junio & Julio & Agosto \\
\hline & \multicolumn{3}{|c|}{ ANTES } & \multicolumn{3}{|c|}{ DESPUÉS } \\
\hline & $\operatorname{MES}_{1}$ & $\operatorname{MES}_{2}$ & $\mathrm{MES}_{3}$ & $\operatorname{MES}_{4}$ & MES $_{5}$ & MES 6 \\
\hline $\begin{array}{l}\text { Depósitos Totales/ } \\
\text { PBI }\end{array}$ & $25 \cdot 42 \%$ & $25 \cdot 36 \%$ & $25.60 \%$ & $25.03 \%$ & $25.45 \%$ & $26.22 \%$ \\
\hline Depósitos ALV/PBI & $6.51 \%$ & $6.94 \%$ & $7.19 \%$ & $6.74 \%$ & $6.86 \%$ & $8.01 \%$ \\
\hline Depósitos DA/PBI & $12.17 \%$ & $12.13 \%$ & $11.75 \%$ & $11.62 \%$ & $11.97 \%$ & $11.64 \%$ \\
\hline Depósitos AP/PBI & $6.75 \%$ & $6.29 \%$ & $6.66 \%$ & $6.66 \%$ & $6.63 \%$ & $6.58 \%$ \\
\hline $\begin{array}{l}\text { Créditos Totales/ } \\
\text { PBI }\end{array}$ & $30.74 \%$ & $31.48 \%$ & $32.70 \%$ & $33 \cdot 31 \%$ & $34 \cdot 77 \%$ & $34.03 \%$ \\
\hline $\begin{array}{l}\text { Créditos a } \\
\text { empresas/PBI }\end{array}$ & $20.44 \%$ & $20.87 \%$ & $21.66 \%$ & $22.05 \%$ & $23.01 \%$ & $22.42 \%$ \\
\hline $\begin{array}{l}\text { Créditos a } \\
\text { Personas/PBI }\end{array}$ & $10.30 \%$ & $10.61 \%$ & $11.04 \%$ & $11.26 \%$ & $11.77 \%$ & $11.61 \%$ \\
\hline $\begin{array}{l}\text { Tarjetas de } \\
\text { Crédito/PEA }\end{array}$ & $35.11 \%$ & $35.19 \%$ & $35.46 \%$ & $36.14 \%$ & $36.36 \%$ & $36.26 \%$ \\
\hline $\begin{array}{l}\text { № de TC por cada } \\
\text { 10o,ooo hab. }\end{array}$ & 35106.87 & 35185.83 & 35461.20 & 36138.53 & 36359.83 & 36257.50 \\
\hline $\begin{array}{l}\text { Tarjetas de } \\
\text { Débito/PEA }\end{array}$ & $64.11 \%$ & $65.07 \%$ & $65.44 \%$ & $66.14 \%$ & $67.03 \%$ & $67.78 \%$ \\
\hline $\begin{array}{l}\text { № de TD por cada } \\
\text { 10o,ooo hab. }\end{array}$ & 64106.81 & 65073.21 & 65441.92 & 66144.99 & 67034.74 & 67779.74 \\
\hline $\begin{array}{l}\text { № de ATM por } \\
\text { cada 10o,ooo hab. }\end{array}$ & 38.37 & 38.37 & 40.63 & 39.41 & 41.85 & 42.44 \\
\hline $\begin{array}{l}\text { № de oficinas por } \\
\text { cada 10o,ooo hab. }\end{array}$ & 9.85 & 9.85 & 9.85 & 10.00 & 10.00 & 10.15 \\
\hline
\end{tabular}

${ }^{*} A L V=$ Depósitos a la vista, $D A=$ depósitos de ahorro, $A P=$ depósitos a plazo.

** $T C=$ tarjetas de crédito, $T D=$ tarjetas de débito, $A T M=$ cajeros electrónicos (siglas en inglés)

${ }^{* * *}$ Fuente: ASBANC, INEI, BCRP.

Viendo la Tabla 2, notamos que el nivel de luego aumentó significativamente en los bancarización en base al ratio de depósitos meses de julio y agosto, mostrando un claro totales sobre PBI, disminuyó en junio, pero avance desde el mes de marzo. 
En cuanto a tarjetas de crédito vemos que éstas tienen en todos los meses, una menor proporción que las tarjetas de débito, es decir, que es más fácil acceder a una tarjeta de débito que de crédito, pero aun así, la tendencia de ambas tarjetas es creciente en el tiempo. De igual manera, se observa una ligera expansión en el número de Cajeros automáticos (ATM) y sucursales bancarias, expresada en los ratios por cada 100,00o habitantes. Esto sugiere una mayor preocupación del sistema financiero por la accesibilidad de todos los usuarios a sus agencias y servicios, lo que los lleva a situarse en más puntos de la ciudad.
De igual forma, se puede observar que el mayor crecimiento corresponde a los depósitos a la vista, con una variación positiva promedio mensual de casi un $1.63 \%$, mientras que los depósitos de ahorro y a plazo lo han hecho a una tasa promedio de $0.18 \%$ y $0.14 \%$ respectivamente. En el caso de los créditos, la mayor tasa de crecimiento promedio mensual corresponde a créditos a grandes empresas, con una tasa de $4.64 \%$, seguidos por los créditos de consumo e hipotecario con un $3.41 \%$ y $3.82 \%$ respectivamente, mientras que en último lugar se encuentra el crédito a micro empresas con apenas un crecimiento promedio mensual de $2.32 \%$.

Tabla 3.

Porcentaje que representan los tipos de créditos y depósitos

(en términos monetarios)

\begin{tabular}{|c|c|c|c|c|c|c|}
\hline \multirow{3}{*}{$\begin{array}{l}\text { Porcentaje que } \\
\text { representan los } \\
\text { tipos de créditos y } \\
\text { depósitos del total }\end{array}$} & Marzo & Abril & Mayo & Junio & Julio & Agosto \\
\hline & \multicolumn{3}{|c|}{ ANTES } & \multicolumn{3}{|c|}{ DESPUÉS } \\
\hline & MES 1 & $\operatorname{MES}_{2}$ & $\mathrm{MES}_{3}$ & $\operatorname{MES}_{4}$ & $\operatorname{MES}_{5}$ & MES 6 \\
\hline $\begin{array}{l}\text { Depósitos totales } \\
\text { en el Sistema } \\
\text { financiero * }\end{array}$ & $100.00 \%$ & $100.00 \%$ & $100.00 \%$ & $100.00 \%$ & $100.00 \%$ & $100.00 \%$ \\
\hline Depósitos a la vista & $25.60 \%$ & $27 \cdot 37 \%$ & $28.10 \%$ & $26.95 \%$ & $26.93 \%$ & $30.53 \%$ \\
\hline Depósitos de ahorro & $47.86 \%$ & $47.82 \%$ & $45.90 \%$ & $46.44 \%$ & $47.03 \%$ & $44.37 \%$ \\
\hline Depósitos a plazo & $26.55 \%$ & $24.81 \%$ & $26.00 \%$ & $26.61 \%$ & $26.04 \%$ & $25.10 \%$ \\
\hline $\begin{array}{l}\text { Crédito en el } \\
\text { Sistema financiero * }\end{array}$ & $100.00 \%$ & $100.00 \%$ & $100.00 \%$ & $100.00 \%$ & $100.00 \%$ & $100.00 \%$ \\
\hline Crédito corporativo & $19.68 \%$ & $19.20 \%$ & $18.10 \%$ & $18.87 \%$ & $19.19 \%$ & $19.29 \%$ \\
\hline $\begin{array}{l}\text { Crédito a grandes } \\
\text { empresas }\end{array}$ & $17.08 \%$ & $17.46 \%$ & $18.23 \%$ & $17.60 \%$ & $17.91 \%$ & $17.37 \%$ \\
\hline $\begin{array}{l}\text { Crédito a medianas } \\
\text { empresas }\end{array}$ & $18.97 \%$ & $18.70 \%$ & $18.92 \%$ & $18.79 \%$ & $18.26 \%$ & $18.44 \%$ \\
\hline $\begin{array}{l}\text { Crédito a pequeñas } \\
\text { empresas }\end{array}$ & $8.75 \%$ & $8.85 \%$ & $8.93 \%$ & $8.84 \%$ & $8.87 \%$ & $8.91 \%$ \\
\hline $\begin{array}{l}\text { Crédito a } \\
\text { microempresas }\end{array}$ & $2.02 \%$ & $2.09 \%$ & $2.05 \%$ & $2.12 \%$ & $1.94 \%$ & $1.87 \%$ \\
\hline Crédito de consumo & $17.99 \%$ & $18.08 \%$ & $18.07 \%$ & $18.10 \%$ & $18.04 \%$ & $18.18 \%$ \\
\hline $\begin{array}{l}\text { Crédito hipotecario } \\
\text { de viviendas }\end{array}$ & $15.51 \%$ & $15.62 \%$ & $15.70 \%$ & $15.69 \%$ & $15.80 \%$ & $15.94 \%$ \\
\hline
\end{tabular}

*Fuente: ASBANC, INEI, BCRP. 
Habiéndose encontrado variaciones positivas en el periodo analizado para todos los indicadores, se procedió a determinar la significancia de estas variaciones a través de la prueba $t$ student. Se trabajó con un nivel de confianza de $99 \%$ ( $\mathrm{p}<0.01$ ), obteniendo los resultados expresados en la Tabla 4.
Como puede observarse en la tabla, todas las variaciones experimentadas por los indicadores resultan significativas, excepto la de los ratios de Tarjetas de crédito sobre PEA y Tarjetas de crédito por cada 100,000 habitantes.

Tabla 4.

Determinación de las variaciones significativas entre el antes y el después de la aplicación de la Campaña "Hablemos más Simple"

\begin{tabular}{|c|c|c|c|}
\hline RATIOS & t obtenida & t crítica & $\mathbf{p}$ \\
\hline Depósitos Totales/PBI & -0.298482891 & $+/-4.6041$ & \multirow{13}{*}{0.01} \\
\hline Depósitos ALV/PBI & -0.71189868 & $+/-4.6041$ & \\
\hline Depósitos DA/PBI & 1.559071577 & $+/-4.6041$ & \\
\hline Depósitos AP/PBI & -0.407363648 & $+/-4.6041$ & \\
\hline Créditos Totales/PBI & -3.367401369 & $+/-4.6041$ & \\
\hline Créditos a empresas/PBI & -3.324040474 & $+/-4.6041$ & \\
\hline Créditos a Personas/PBI & -3.388475816 & $+/-4.6041$ & \\
\hline Tarjetas de Crédito/PEA & -8.005855972 & $+/-4.6041$ & \\
\hline $\begin{array}{l}\text { Número de TC por cada } \\
\text { 100,ooo habitantes }\end{array}$ & -8.005855972 & $+/-4.6041$ & \\
\hline Tarjetas de Débito/PEA & -3.419093534 & $+/-4.6041$ & \\
\hline $\begin{array}{l}\text { Número de TD por cada } \\
\text { 100,ooo habitantes }\end{array}$ & -3.419093534 & $+/-4.6041$ & \\
\hline $\begin{array}{l}\text { Número de ATM por cada } \\
\text { 100,ooo habitantes }\end{array}$ & -1.768958192 & $+/-4.6041$ & \\
\hline $\begin{array}{l}\text { Número de oficinas por cada } \\
\text { 10o,ooo habitantes }\end{array}$ & -4 & $+/-4.6041$ & \\
\hline
\end{tabular}

Este aumento significativo en todos los ratios que miden la bancarización podría sugerir que se esté mejorando los niveles de la misma en la ciudad, y que una de las razones de esto sea la campaña "Hablemos más Simple”. Pero, como se expuso anteriormente, los métodos para determinar los niveles de bancarización en un territorio son de lo más variados.
Aplicando la metodología convencional, se considerará el Ratio de Depósitos totales sobre PBI como el determinante del nivel de bancarización en la ciudad durante el periodo analizado. De este modo tenemos que el nivel de bancarización en Arequipa alcanzado a tres meses de la implementación de la Campaña "Hablemos más simple" es de $26,22 \%$. 


\section{Discusión}

Contrario a lo explicado por José Gómez de La Torre (2011), jefe de la Oficina Descentralizada de la Superintendencia de Banca y Seguros de Arequipa (SBS), la bancarización en Arequipa obtenida para el periodo marzo-agosto del presente año no supera el promedio nacional. Incluso se experimentó un retroceso en el nivel de bancarización con respecto al obtenido el año anterior (34,08\% frente al 26,22\% actual). Según de Gómez de la Torre (2011), el incremento en la bancarización arequipeña se debería a la reciente apertura de los megacentros comerciales, que privilegian el uso de créditos y tarjetas para la realización de las compras. Contrastando esto con la información obtenida, podemos afirmar que si bien el uso de servicios bancarios se ha incrementado, la tasa de crecimiento de éstos, especialmente la de depósitos, no es superior a la tasa de crecimiento del PIB arequipeño producto del boom comercial experimentado en la ciudad. Esto explicaría el por qué de la baja de la bancarización arequipeña en este periodo de tiempo.

Según expertos una "adecuada y decisiva estrategia de bancarización puede convertir al sistema financiero en un eficiente vehículo de inclusión social, pues la micro y pequeña empresa en el país generan aproximadamente el $42 \%$ del PBI, emplean a cerca del $77 \%$ de la población económicamente activa, y explican cerca del $95 \%$ del empresariado nacional" (Ophelimos, 2011, párr. 9). Podemos ver que en nuestra ciudad, independientemente del nivel de bancarización alcanzado, no se hace una bancarización adecuada porque el mercado más desatendido en el Perú y en nuestra ciudad es, la pequeña y la micro empresa, pues como se vio en los resultados, éstas presentan el menor porcentaje de créditos otorgados en términos monetarios, siendo quienes más acceso al crédito requieren. Producto de la falta de atención de las instituciones financieras a este sector, se desata la informalidad, impidiendo el logro de un uso masivo y total del sistema financiero, afectando la bancarización. Es así como una inadecuada focalización de los servicios bancarios se torna en un círculo vicioso que impide el avance de la bancarización en la ciudad a un ritmo coherente con el desarrollo de la economía.

De igual forma en la estructura de los depósitos que perciben los bancos, se ve que los depósitos de mayor proporción son los de ahorro, cuya característica es de permitir al ahorrista retirar sus ahorros en el corto plazo en el momento que lo desee. Los bancos funcionan como intermediarios, captan el excedente de unos y se los prestan a otros con carencia de capital, ahora bien, dada la naturaleza de este tipo de depósitos y la posibilidad de los ahorristas de retirar su dinero en cualquier momento, es que el banco debe manejar adecuadamente los calces de plazo para los créditos y fomentar el uso de instrumentos como los depósitos a plazo, cuya movilidad del capital se ve restringida por un mayor horizonte de tiempo.

Este tipo de depósitos se convierten en los más provechosos y beneficiosos para el otorgamiento de créditos, pero lamentablemente este tipo de depósitos representan una porción significativamente menor dentro de todos los tipos de captaciones del banco. Es por esa razón por la cual podría 
producirse un descalce en los plazos de captación-crédito, afectando sobre todo a los microempresarios, quienes por la naturaleza de sus negocios emergentes, se prestan a plazos prolongados y altas tasas, representando riesgos de cobro altísimos para los bancos. Muy por el contrario las corporaciones y grandes empresas tienen una capacidad financiera para pagar de manera más rápida, y adicionalmente el riesgo de cartera pesada disminuye. Con lo cual el calce de plazos de las instituciones financieras se vuelve estable.

Adicionalmente sería óptimo saber cuáles son las razones por las que no se opta por depositar el excedente a plazo fijo, puesto que algunas investigaciones señalan que el porcentaje destinado a depósitos a plazo fijo deber ser el 10\% del PBI (BCRP, 2011), que en nuestro caso no se da, y es que otros factores como la inestabilidad política y financiera crean en el ahorrista arequipeño y peruano un temor a posibles cambios en el futuro, haciendo que se frene el nivel de bancarización y por ende el desarrollo económico.

Con respecto a la Campaña "Hablemos más Simple" podemos constatar que sus iniciativas no han rendido el fruto deseado en nuestra ciudad en términos de aumento de la bancarización. Si bien el uso de servicios financieros se ha incrementado, podemos constatar que el mayor incremento se da en rubros como otorgamiento de tarjetas de crédito y débito, aumento de cajeros automáticos y en el caso de créditos, aquellos destinados a empresas. Por otro lado, las diferencias experimentadas en créditos personales, y depósitos no son suficientes para elevar el nivel de bancarización arequipeña de manera congruente con el crecimiento del Producto Interno Bruto. Cabe recordar que la iniciativa principal de la campaña fue la de informar a los usuarios acerca de los servicios financieros y estimular su uso mediante una mayor posibilidad de acceso (ASBANC, 2012). Dicho objetivo no se tradujo en mejoras significativas respecto del nivel de bancarización, pues como se constata en los resultados, el incremento en el uso de los servicios financieros se dio principalmente en el rubro empresarial en el caso de los créditos, y en otros instrumentos financieros como tarjetas que no poseen un peso determinante en la bancarización de un territorio (recuérdese que el aumento de tarjetas de crédito en la PEA no mostró una diferencia significativa). Por otro lado, aunque el número de sucursales y cajeros automáticos en la ciudad se haya incrementado, esto no significa necesariamente que una mayor parte de la población esté accediendo a los mismos.

En conclusión, constatamos una disminución en el nivel de bancarización de la ciudad de Arequipa producto de un incremento del uso de los servicios financieros menor al crecimiento económico de la ciudad. Además, la campaña "Hablemos más simple" en sus tres primeros meses de aplicación, no ha rendido los frutos previstos en materia de bancarización, pues no ha demostrado acercar más a los usuarios al uso de servicios e instrumentos financieros de peso predominante en el nivel de bancarización de un territorio, como son los depósitos y créditos personales. Esto puede implicar también, que aún entre el sistema financiero y los usuarios (personas naturales sobre todo), no existe un nivel 
de confianza adecuado, que permita que los mismos accedan a depósitos a largo y mediano plazo en su mayoría, o créditos personales.

Como limitaciones del estudio consideramos el corto horizonte de tiempo sobre el que se aplicó el análisis, lo que pudo hacer que el nivel de bancarización de la ciudad luego de tres meses de implementada la campaña sea bajo. Por ser una iniciativa recién implementada, puede que aún no haya logrado el efecto que planteó inicialmente, y que sea cuestión de tiempo para observar resultados favorables. En posteriores estudios podría analizarse el efecto de la campaña transcurrido un tiempo prolongado, lo cual permitiría tener mayor certeza de sus efectos en el nivel de bancarización arequipeña.

\section{Referencias}

Almendárez, J. (2008). “Banco Atlántida: el proyecto de bancarización más grande". (Documento en formato html) Recuperado el o9 de Noviembre del 2012 de: http://www.gbm.net/bt/bt4o/ historias_exito/banco_atlantida.php

Araya, C. \& Cols. (2012). "Masificación de los medios de pago: Barreras de adopción de la tecnología financiera”. Santiago de Chile: Universidad Andrés Bello.

Arroyo, E. (2008). "Bancarización en el Perú. Asociación de Bancos del Perú (ASBANC)”. (Documento en formato html) Recuperado el 11 de Noviembre del 2012 de: www.asbanc.com/index.html

Asociación de Bancos del Perú. (2012). “Campaña Hablemos más Simple”.
(Documento en formato HTML) Recuperado el 19 de Noviembre del 2012 de: www.hablemosmassimple.com/ index.html

Banco Central de Reserva del Perú. (2011). "Concentración bancaria y margen de las tasas de Interés en Perú”. Lima: BCRP.

Burneo, K. (2009). "Bancarización pública en el Perú: Efectos sobre el crecimiento económico regional”. Lima: VDM Publishing.

Conde, C. (2007). "Financiamiento del crecimiento económico". Ciudad de México, D. F.: Editorial Porrua.

Gestión. (2008). “Bancarización en el Perú creció los últimos seis años”. (Documento en formato html) Recuperado el 22 de Noviembre del 2012 de: http:// gestion.pe/noticia/319607/bancarizacion-peru-crecio-ultimos-seis-anos

Gestión. (2012). “Campaña Hablemos más simple”. (Documento en formato html) Recuperado el 21 de Noviembre del 2012 de: http://blogs.gestion. pe/gestiondeservicios/2012/o7/hablemos-mas-simple.html

Furtado, C. (1974). “Teoría política del desarrollo economico”. 15va. Edición. Sao Paulo: Siglo Veintiuno Editores.

Gómez de la Torre, J. (2011). "La bancarización en Arequipa es mayor que el promedio". (Documento en formato html) Recuperado el 17 de Noviembre del 2012 de: http://www.larepublica. 
pe/16-03-2012/bancarizacion-en-arequipa-es-mayor-que-el-promedio

IPSCuba. (2010). "Bancarización”. (Documento en formato html) Recuperado el 12 de octubre del 2012 de: http:// www.ipscuba.net/index.php?option=com_k2\&view=item\&id=379:bancarizaci $\% C_{3} \% B_{3}$ \& Itemid=10

Inga, P. (2010). "Bancarización”. (Documento en formato html) Recuperado el o5 de Noviembre del 2012 de: http://institutodelperu.org.pe/index.php?option=com_content\&task=view\&id=977\&Itemid=130

Jiménez, L. y Manuelito, S. (2012). "Los mercados financieros en América Latina y el financiamiento de la inversión:hechos estilizados y propuestas para una estrategia de desarrollo". Santiago de Chile: CEPAL - ONU.

Loayza N.; Fajnzylber R. y Calderón A. (2005). "Economic growth in Latin America and the Caribbean. stylized facts, explanations and forecasts". 6ta. Edición. Washington, D. C.: World Bank.

Luzón, F. (2002). "Bancarizar a la población: La nueva frontera latinoamericanos”. Buenos Aires: Editorial Herder.
Ophelimos. (2011). "La bancarización en el Perú y los nuevos retos del sistema financiero". (Documento en formato html) Recuperado el 22 de Noviembre del 2012 de:: http://blog.pucp.edu.pe/item/17120/ la-bancarizacion-en-el-peru-y-los-nuevos-retos-del-sistema-financiero

Superintendencia de Banca y Seguros. (2010). "Bancarización en Perú alcanza el 30.2\%”. (Documento en formato html) Recuperado el 18 de Noviembre del 2012 de: http://www.rpp.com.pe/2011-o4-o6bancarizacion-en-el-peru-alcanza-el30-2-noticia_352863.html

Superintendencia de Banca y Seguros . (2011). "Perú: indicadores de inclusión financiera, de los sistemas financiero, de seguros y de pensiones". (Documento en formato pdf) Recuperado el 18 de noviembre del 2012 de: http://intranet1.sbs.gob.pe/ estadistica/financiera/2011/Diciembre/ CIIF-ooo1-dizo11.PDF

Superintendencia de Banca y Seguros. (2012). "Plan Nacional de difusión del rol y funcionamiento del Sistema financiero peruano”. Lima: SBS.

Zahler, R. (2010). "Bancarización privada en Chile”. New York: ONU. 